\title{
Chapter 9 \\ Synthesis: Managing Socio-ecological Production Landscapes and Seascapes for Sustainable Communities in Asia
}

\author{
Osamu Saito, Suneetha M Subramanian, Shizuka Hashimoto, \\ and Kazuhiko Takeuchi
}

\begin{abstract}
While Chaps. 2-5 covered specific case studies of landscapes and seascapes in Japan (Chaps. 2-4) and Bangladesh (Chap. 5), Chaps. 6-8 consisted of a series of review articles on sustainable management approaches relating to land/ seascapes that explored lessons learned from assessing resilience in socio-ecological production landscapes and seascapes (SEPLS) (Chap. 6), solutions for sustainable management of SEPLS in Asia (Chap. 7), and the effectiveness of biodiversity science-policy interfaces (SPIs) from local to global scales (Chap. 8). These chapters are summarized here according to their objectives, materials/study sites, methods/ tools, spatial scales, and key actors. Then, the implications for the United Nations Convention on Biological Diversity (CBD) Post-2020 Global Biodiversity Framework are discussed using key leverage points of transformations toward sustainability identified by the Intergovernmental Science-Policy Platform on Biodiversity and Ecosystem Services (IPBES) Global Assessment: (1) visions of a good life; (2) total consumption and waste; (3) values and action; (4) inequalities;
\end{abstract}

\footnotetext{
O. Saito $(\bowtie)$

United Nations University Institute for the Advanced Study of Sustainability (UNU-IAS), Shibuya, Tokyo, Japan

Institute for Global Environmental Strategies (IGES), Hayama, Kanagawa, Japan Institute for Future Initiatives (IFI), The University of Tokyo, Bunkyo, Tokyo, Japan e-mail: saito@unu.edu

S. M. Subramanian

United Nations University International Institute for Global Health (UNU-IIGH), Cheras, Kuala Lumpur, Malaysia

S. Hashimoto

Graduate School of Agriculture and Life Sciences, The University of Tokyo, Bunkyo, Tokyo, Japan

K. Takeuchi

Institute for Global Environmental Strategies (IGES), Hayama, Kanagawa, Japan

Institute for Future Initiatives (IFI), The University of Tokyo, Bunkyo, Tokyo, Japan
}

(C) The Author(s) 2020

O. Saito et al. (eds.), Managing Socio-ecological Production Landscapes and Seascapes for Sustainable Communities in Asia, Science for Sustainable

Societies, https://doi.org/10.1007/978-981-15-1133-2_9 
(5) justice and inclusion in conservation; (6) externalities and telecoupling; (7) technology, innovation, and investment; and (8) education and knowledge generation and sharing.

Keywords Socio-ecological production landscapes and seascapes $\cdot$ Ecosystem services · Visualization · Mapping $\cdot$ Stakeholder analysis $\cdot$ Science-policy interface

\subsection{Summary of the Book}

Broadly, this book highlights various approaches to achieving the sustainable use of resources and development for socio-ecological production landscapes and seascapes (SEPLS) from local to global scales. While Chaps. 2-5 covered specific case studies at landscapes and seascapes in Japan (Chaps. 2-4) and Bangladesh (Chap. 5), Chaps. 6-8 consisted of a series of review articles that explored lessons learned from assessing resilience in SEPLS (Chap. 6), solutions for sustainable management of SEPLS in Asia (Chap. 7), and the effectiveness of biodiversity sciencepolicy interfaces (SPIs) from local to global scales (Chap. 8). These chapters are summarized in Table 9.1 according to their objectives, materials/study sites, methods/tools, spatial scales, and key actors.

Focusing on the Sekisei Lagoon, Okinawa Prefecture, at the southeastern tip of the Japanese archipelago, Chap. 2 examined the inter-relationships between the sectoral policy interventions by various marine-related ministries and the entire structure of the integrated ocean policy. This study developed the SES schematic, which summarized and visualized the main ecosystem structures, functions, use types, and stakeholders relating to the lagoon. This SES schematic can be used as a boundary object to facilitate knowledge exchange between various stakeholders, including policy makers, practitioners, and researchers, to share a common understanding of the current situation, and to co-create policy interventions for sustainable uses of not only the Sekisei Lagoon but also other types of ecosystem or natural capital.

Chapter 3 focused on quantifying the willingness of tourists to participate in invasive carp removal in nature-based tourism in Amami Oshima, Japan. The study found that most tourists would avoid participating in carp removal activities as a tour option without any financial discounts but that over one third of tourists were willing to work for carp removal based on their own motivations. This result suggests that tourists could play an important role in invasive alien species management.

Using the example of the city of Toyama in Japan, Chap. 4 focused on a participatory approach of backcasting scenario-making to identify ways of bringing together various perspectives for sustainable urban planning. The chapter concluded that, when governed in certain ways, citizen participatory approaches can realize a fairly good balance between diverged processes and converged outcomes of backcasting scenario-making on the issue of urban sustainability transitions.

Chapter 5 highlighted how local institutions and traditional knowledge can be incorporated when addressing sustainable use and the conservation of biodiversity, focusing on experiences from the Sundarbans area in Bangladesh. Following MEB approaches, the chapter concluded that human sociality-based conservation 


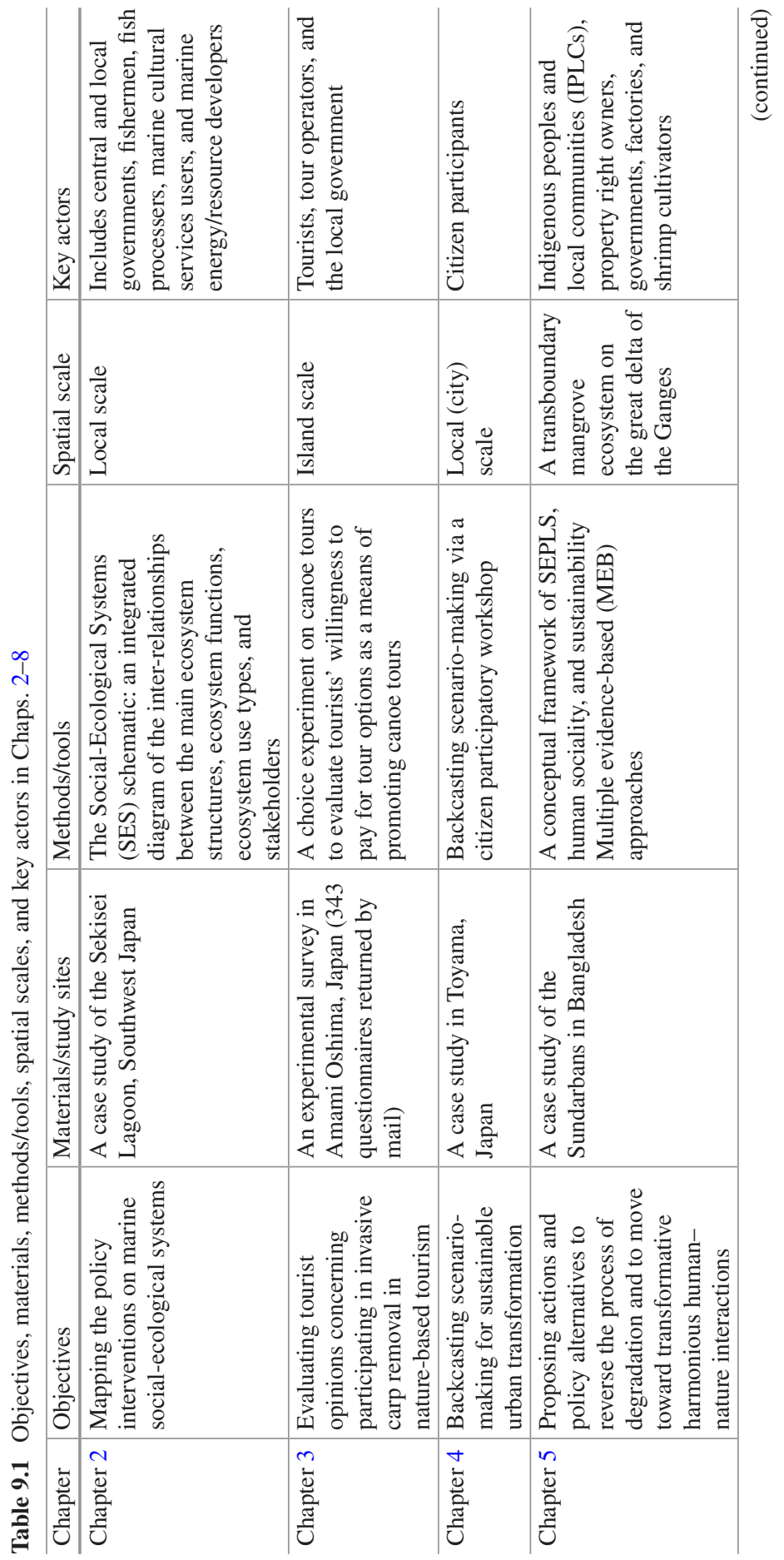




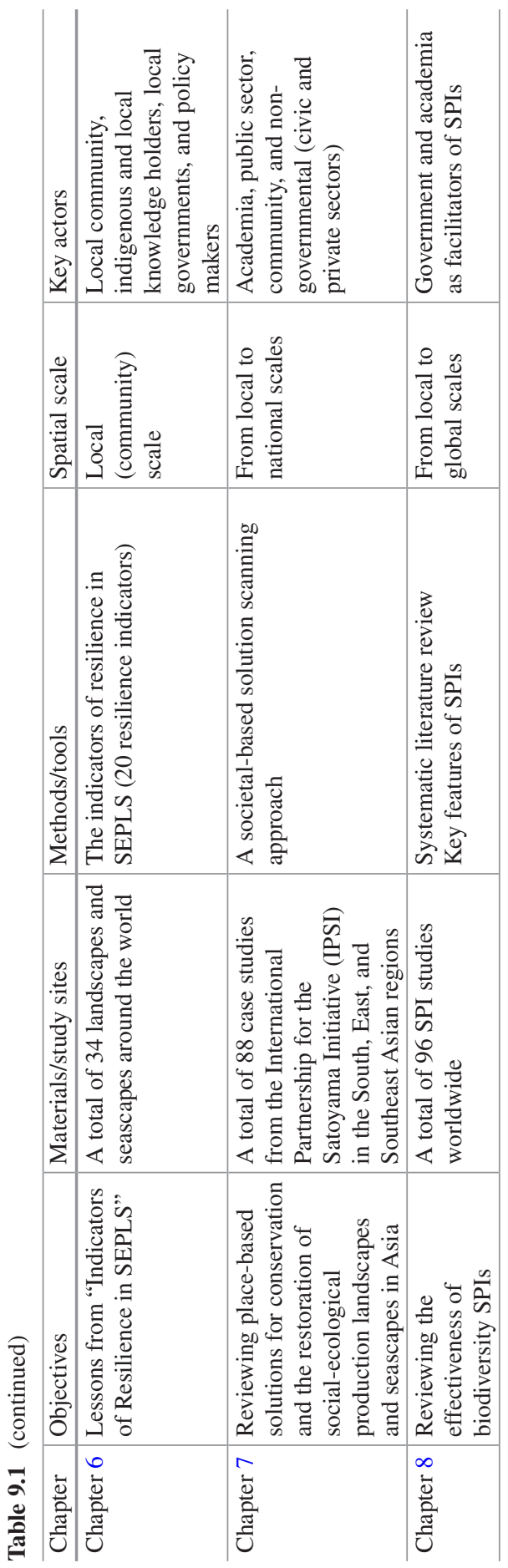


practices positively impact resilient indicators and help achieve the Aichi Biodiversity Targets.

Chapter 6 examined applying the resilience assessment process using an indicator-based approach at 34 sites (communities) of SEPLS in different regions of the world. The measurement criteria are defined by individual communities, and therefore, the outcomes are specific to those communities when understanding the multiple aspects of resilience and changes over time and identifying important issues for improving the resilience of a community. The most prominent benefit found when using the indicators is their value as a convening tool, bringing together multiple stakeholders in a landscape or seascape.

Chapter 7 identified various categories of place-based solutions for the sustainable management of SEPLS based on the experiences of partners from the South, East, and Southeast Asian countries of the International Partnership for Satoyama Initiative (IPSI). Sharing knowledge of various place-based solution types in different social-ecological contexts helps provide more purposeful and deliberate designs of SEPLS with multiple benefits.

Chapter 8 reviewed the effectiveness of biodiversity SPIs by examining the different features of effective SPIs, including capacity building, trust building, adaptability, and continuity. The chapter concluded that effective, interdisciplinary SPIs and timely and relevant inputs for policymakers are required to ensure more dynamic, iterative, and collaborative interactions between policymakers and other actors.

\subsection{Implications for Transformative Changes toward Sustainability}

The IPBES Global Assessment (IPBES 2019) stressed that "goals for conserving and sustainably using nature and achieving sustainability cannot be met by current trajectories, and goals for 2030 and beyond may only be achieved through transformative changes across economic, social, political and technological factors." It is necessary for us to conserve, restore, and use nature sustainably while simultaneously meeting other global societal goals through extensive efforts that foster transformative change. Transformations toward sustainability can be triggered by following key leverage points: (1) visions of a good life; (2) total consumption and waste; (3) values and action; (4) inequalities; (5) justice and inclusion in conservation; (6) externalities and telecoupling; (7) technology, innovation, and investment; and (8) education and knowledge generation and sharing (IPBES 2019). Regariding these leverage points, Table 9.2 summarizes relevant approaches and insights linked to these leverage points as highlighted by the different experiences captured in this book. The Convention on Biological Diversity (CBD) has also been advocating the need to have a systems approach to address conservation and human well-being 


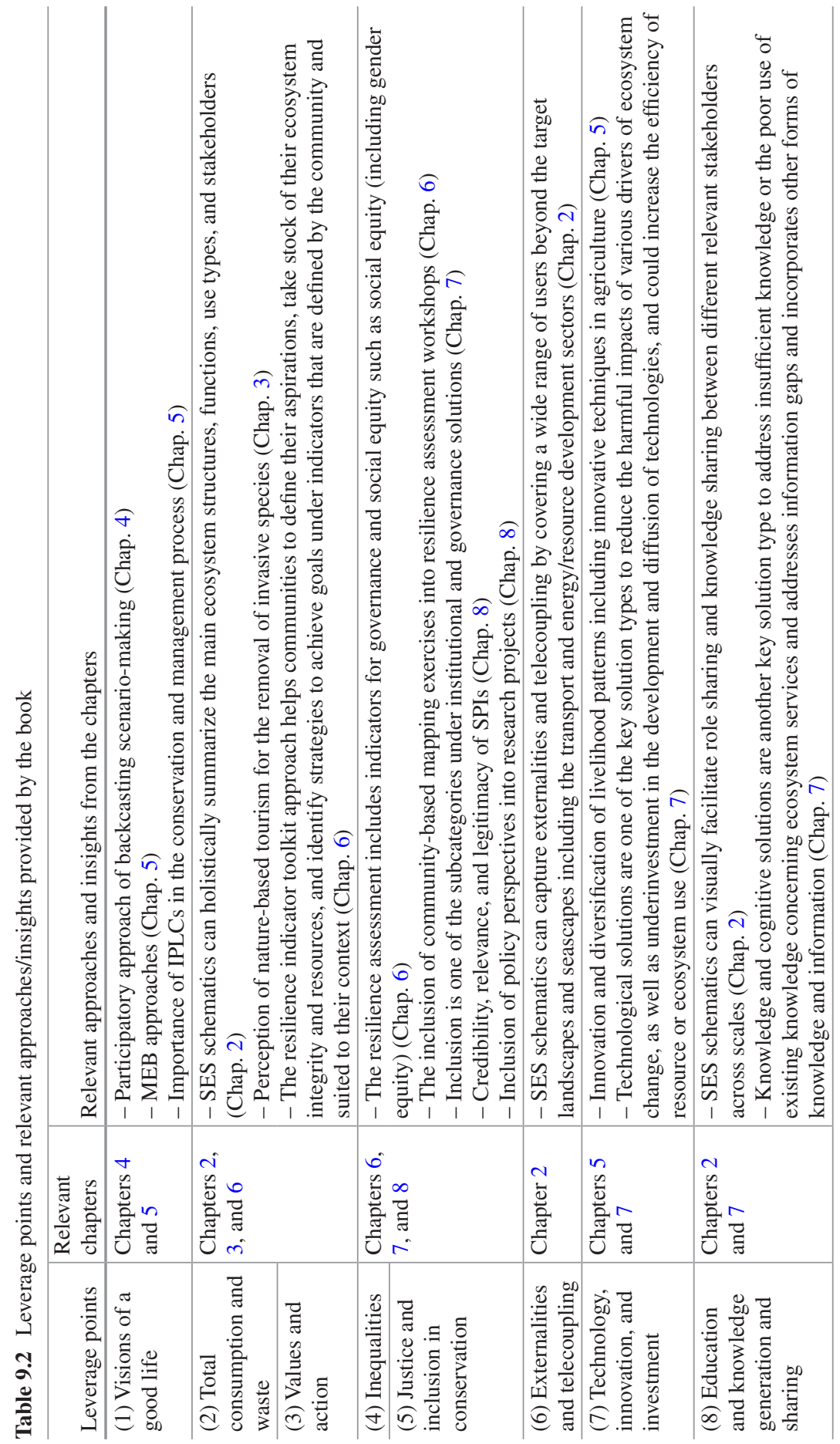


needs and has been emphasizing the need to embark on transformative change and manage transitions toward sustainable pathways (CBD 2017, 2018).

\subsection{Afterword: Future Research Directions}

This book presents contemporary experiences and analyses of community-based approaches to the sustainable resource management of SEPLS primarily based on experiences in Asia. The different cases highlight several pertinent issues regarding land/seascape approaches. First, empirical evidence illustrating the relevance of landscape approaches to the conservation of natural resources, contributions to economies, and sustainable livelihoods is compelling. The landscape approach is by nature an integrated approach that cuts across sectoral divisions and various policy priorities (e.g., environment, rural development, water management, health, and food security) and has a systemic focus on both the ecological and social dimensions within the land/seascape.

This implies that the interconnectedness of natural and human systems is highly entrenched in such areas and that the utilization and management of resources, even if driven by contextual priorities, have certain broad similarities, including those related to maintaining the multifunctionality of the landscape and ensuring a diversity of resources, a diversity of income sources based on primary production and services, and endogenous approaches that integrate traditional and modern practices and knowledge to ensure more sustainable outcomes. However, the experiences related in this book also indicate that sustaining such an ideal and idyllic scenario is fraught with various challenges ranging from policy drivers, changing priorities of the local population, demographic changes, the impact of distant market forces, the erosion of traditional practices, the homogenization of cropping practices, and changes in land use.

Addressing these challenges requires a comprehensive approach beginning with a clear understanding of changes in the natural resources and in the various drivers of change and of the implications for a good quality of life for the population. Possible solutions and pathways for the development that are participatory and inclusive in nature and ensuring a good alignment between macro policy goals and landscape level priorities need to be identified and implemented. New solutions may require the creation of flexible legal frameworks that protects the interests of, and reduces political constraints for, collaborative efforts in land/seascapes (Plieninger et al. 2018). This also implies an enhanced mandate for future research priorities focused on integrated approaches to landscape management to build inventories on the management, natural state, and drivers of change; to develop methodologies that further high fidelity scenarios developed using participatory approaches involving stakeholders on the ground; and to ensure that actions are taken at multiple scales, including local, regional, and beyond, and are aligned with new conceptual and 
policy concepts related to nature's contributions to people and sustainable development goals (Saito and Ichikawa 2014; Saito 2017). A global IPBES assessment identified similar gaps in knowledge, research, and resources (IPBES 2019). It is clear from the case studies in this book that it is possible to compare various policy outcomes from real-world experiences. Such experiences also highlight the utility of incorporating other ways of knowing, including data and trends of natural resources as observed by local communities, well-being parameters, and related drivers of change that can enhance existing knowledge of these subjects.

The effectiveness of any policy is reflected in how it is adopted and deployed by the people who are considered the most proximate stakeholders, whether in terms of resource proximity and/or impacts of outcomes. To ensure adoption, it is important that policies are sensitive to the priorities and challenges of such stakeholders. The chapters in this book provide a snapshot of possible approaches to streamline local and mainstream socio-ecological goals. We hope that it will serve to foster more creative thinking and support toward the revitalization of dynamic socio-ecological systems, enabling locally led conservation actions and broad-based development across different regions of the world.

Acknowledgments This book was funded by the EnvironmentvResearch and Technology Development Fund (S-15 "Predicting and Assessing Natural Capital and Ecosystem Services" (PANCES), Ministry of the Environment, Japan). We also acknowledge various contributions by International Partnership for the Satoama Initiative (IPSI).

\section{References}

CBD (2017) Discussion note on toward a transformative change for biodiversity based on systems transition. https://www.cbd.int/cooperation/bogis/S111.pdf

CBD (2018) Press release. https://www.cbd.int/doc/press/2018/pr-2018-07-18-sbstta22-sbi2-en. pdf

IPBES (2019) Summary for policymakers of the global assessment report on biodiversity and ecosystem services of the Intergovernmental Science-Policy Platform on Biodiversity and Ecosystem Services, IPBES/7/10/Add.1. https://www.ipbes.net/system/tdf/ipbes_7_10_add1-_advance_0.pdf?file $=1 \&$ type $=$ node $\&$ id $=35245$

Plieninger T, Kohsaka R, Bieling C, Hashimoto S, Kamiyama C, Kizos T, Penker M, Kieninger P, Shaw BJ, Sioen GB, Yoshida Y, Saito O (2018) Fostering biocultural diversity in landscapes through place-based food networks: a "solution scan" of European and Japanese models. Sustain Sci 13:1-15. https://doi.org/10.1007/s11625-017-0455-z

Saito O (2017) Future science-policy agendas and partnerships for building a sustainable society in harmony with nature. Sustain Sci 12:895-899. https://doi.org/10.1007/s11625-017-0475-8

Saito O, Ichikawa K (2014) Socio-ecological systems in paddy-dominated landscapes in Asian Monsoon. In: Nishikawa U, Miyashita T (eds) Social-ecological restoration in paddydominated landscapes. Springer, New York, pp 17-37 
Open Access This chapter is licensed under the terms of the Creative Commons Attribution 4.0 International License (http://creativecommons.org/licenses/by/4.0/), which permits use, sharing, adaptation, distribution and reproduction in any medium or format, as long as you give appropriate credit to the original author(s) and the source, provide a link to the Creative Commons licence and indicate if changes were made.

The images or other third party material in this chapter are included in the chapter's Creative Commons licence, unless indicated otherwise in a credit line to the material. If material is not included in the chapter's Creative Commons licence and your intended use is not permitted by statutory regulation or exceeds the permitted use, you will need to obtain permission directly from the copyright holder. 